Research Article

\title{
Knowledge and Practice of Employed Mothers towards Exclusive Breastfeeding and Its Associated Factors in Mecha District, Northwest Ethiopia
}

\author{
Amare Lisanu Mazengia $\mathbb{D}^{1}$ and Hibru Demissie ${ }^{2}$ \\ ${ }^{1}$ College of Health Sciences, Salale University, Fiche, Ethiopia \\ ${ }^{2}$ Nutrition and EPI Officer, Mecha District Health Office, Mecha, Ethiopia \\ Correspondence should be addressed to Amare Lisanu Mazengia; amarelm21@yahoo.com
}

Received 14 March 2020; Revised 18 September 2020; Accepted 5 November 2020; Published 16 November 2020

Academic Editor: C. S. Johnston

Copyright (c) 2020 Amare Lisanu Mazengia and Hibru Demissie. This is an open access article distributed under the Creative Commons Attribution License, which permits unrestricted use, distribution, and reproduction in any medium, provided the original work is properly cited.

\begin{abstract}
Background. Exclusive breastfeeding is an important strategy for improving child health. However, the practice of exclusive breastfeeding among employees is very low in developing countries including Ethiopia. Objective. The objective of this study was to assess the knowledge and practice of employed mothers towards exclusive breastfeeding and its associated factors in Mecha district, Amhara Region, Northwest Ethiopia, 2019. Methods. A cross-sectional study was conducted from April 05 to June 30 , 2019. A stratified random sampling technique was applied. Data were analyzed using statistical package for social sciences (SPSS) version 23 software. Multivariate logistic regression was used to determine predictors of knowledge and practice. Result. A total of 449 participants were enrolled with a response rate of $95.54 \%$. The study revealed that $92.1 \%$ (95\% CI: (89.5-94.6)) of participants had good knowledge. However, only 38.5\% (95\% CI: (33.8-42.9)) employed mothers breastfeed their babies exclusively. Certain predictors such as maternity leave $(\mathrm{AOR}=0.31,95 \% \mathrm{CI}:(0.10-0.91)$, $p$ value $=0.03)$, mothers' level of education $(\mathrm{AOR}=2.97,95 \%$ CI: (1.66-5.34), $p$ value $<0.001)$, support from husbands(AOR $=0.26,95 \%$ CI $(0.14-0.47)$, $p$ value $<0.001)$, and actual time to return back to their work $(\mathrm{AOR}=0.21 ; 95 \% \mathrm{CI}$ : $(0.08-0.51), p$ value $=0.01)$ were statistically associated with exclusive breastfeeding. Conclusions and Recommendations. The knowledge and practice of employed mothers towards exclusive breastfeeding were affected by the number of predictors. Exclusive breastfeeding practice among employed mothers was low. It is advisable to give some flexible working hours for breastfeeding mothers.
\end{abstract}

\section{Introduction}

Appropriate exclusive breastfeeding (EPF) practice is defined as feeding only breast milk and no other liquids or solids, even water, with the exception of medicines prescribed by health professionals to the child age less than 6 months of age [1]. Human milk is a God-given natural phenomenon; the hormonal and immunological constituent of human milk provides growth and development to the brain, contributing to the motor and sensory [2]. Moreover, breastfeeding [3] has countless advantages including emotional attachment, being economically sound, and physical remuneration to the mother's wellbeing. Breastfeeding is an important public health strategy for improving infant and child morbidity and mortality, improving maternal morbidity, and helping to control healthcare costs. Breastfeeding is associated with a reduced risk of otitis media, gastroenteritis, respiratory illness, sudden infant death syndrome, necrotizing enter colitis, obesity, and hypertension [4]. Nutritional deficiencies and infectious diseases are the leading causes of child mortality in developing countries. Breastfed infants have a reduced risk of malnutrition and common childhood infectious diseases [5-7]. Globally, 60\% of the 10.9 million under-five children death annually occur due to malnutrition, inappropriate infant feeding practices, and infectious disease, and over two-thirds of these deaths occur during the first year of life [8]. In developing countries including Ethiopia, appropriate practice of EBF can prevent 
$13 \%$ of under-five mortality [9]. Inappropriate infant feeding practice could have a negative effect on child growth and development where accessibility of basic health serves is not sufficient $[10,11]$. In Ethiopia, almost all children (97\%) are breastfed at some point in the life time. However, only $58 \%$ of infants under the age of 6 months are exclusively breastfed, and exclusive breastfeeding declines with age from $74 \%$ in infants aged $0-1$ months to $36 \%$ in infants aged 4-5 months [12]. In our contemporary society, employed women are actively involved in paid job which has strict laws and codes of conduct which may not enable them to have adequate time to practice exclusive breastfeeding [11]. In Somali regional state of Ethiopia, exclusive breastfeeding practices were very low among employed mothers with a prevalence of 24.8 and $82.9 \%$ in employed and unemployed mothers, respectively [13]. The prevalence of exclusive breastfeeding in the study area was reported as $47 \%$ in infants of aged between 6-12 months [14]. This evidence clearly shows us that the potential public health importance of EBF to reduce the burden of under-five mortality is still untapped in Ethiopia, and employed mothers (mothers who are working for, at least, 8 hours per day outside of their home paid by salary pay roll in order to generating an income for their survival in addition to the work they perform at home in raising their child) stay far apart from their child due to their work. So that, more detailed understanding of the knowledge and practice of employed mothers towards EBF in Ethiopia is needed to develop effective interventions to improve the rates of $\mathrm{EBF}$ and, thus, reduce infant mortality.

\section{Objective}

The study was aimed to assess the level of knowledge and practice of employed mothers towards exclusive breastfeeding and associated factors in Mecha district, Northwest Ethiopia, 2019.

\section{Methods}

3.1. Study Design. An institution-based cross-sectional study design was employed.

3.2. Study Area and Period. The study was carried out in Mecha district which is located $530 \mathrm{~km}$ from Addis Ababa, the capital city of Ethiopia. Based on the 2010 Ethiopian Calendar (E.C.) population profile, Mecha district has a total population of 390, 237, of whom 193,167 are women. As per the official report of Mecha district, currently, the district has 52 kebeles (the smallest administrative structural unit of land within a given population) with a total employed population of 9527 . There are 4655 female employed residents in the district, of which 1497 women employees had children in the age of 6-23 months. The employing organization/facility distribution in the district comprises 10 health centers, 38 health posts and one district hospital, 68 primary schools, six secondary schools, one high school, and 26 office sectors owned by the government. There are also two medium clinics, 10 primary clinics, $10 \mathrm{drug}$ stores and one pharmacy operating in the woreda/district (an administrative structural unit of land which contains many kebeles, or it is an administrative structural unit next to kebele), and 1954 small enterprises. The study was conducted from April 05 to Jun 30, 2019.

3.3. Source and Study Population. The source populations were all employed mothers who had children aged 6-23 months and who were living in Mecha district. All selected employed mothers who had children in the age of 6-23 months living in the district were the study population.

3.4. Eligibility Criteria. In order to examine knowledge and practice of exclusive breastfeeding, the study only integrates employed mothers who had children aged 6 to 23 months. Those mothers who were not biological mothers (care givers) or seriously ill mothers who did not come to the work place at the time of data collection were excluded.

\subsection{Study Variables}

3.5.1. Dependent Variables. Knowledge (good/poor) and practice (appropriate/inappropriate) of exclusive breastfeeding. Appropriate exclusive breastfeeding (EPF) practice is defined as feeding only breast milk and no other liquids or solids, even water, with the exception of medicines prescribed by health professionals to the child age less than 6 months of age. Inappropriate EPF practice is feeding of any solids/liquids in addition to breastfeeding in the first six months of age of infants. Practice-related data collection tools were included; did you provide any additional food for your current child with in the first six months? Did you give water for your current child during the first six months? When did you start first breastfeeding and did you feed the colostrum soon after birth to your new baby? We asked the following ten yes or no knowledge-related questions for employed mothers: 1. breastfed children are more benefitted than formula milkfed children, 2. breast milk contains all the essential nutrients for a newborn child, 3 . breastfeeding is a good contraceptive method, 4 . semisolid/solid foods should be introduced to the baby at six months of age, 5. exclusive breastfeeding does not prohibit giving of water to the infant, 6. breastfeeding promotes mother-baby attachment, 7. immune systems of breastfed infants are more developed than formula-fed infants, 8. did you feed the initial yellow breast milk (colostrum) soon after birth to your new baby? 9. colostrum is nutritionally useless for the baby and should be discarded, and 10. a new born baby should suck breast milk before a minimum of one day following delivery, and each correct answer was given a value of 1 and an incorrect answer a value of 0 . After computing the sum for each respondent and mean, it was dichotomized into having good knowledge for mothers who correctly answered $\geq$ mean and poor knowledge for mothers who correctly answered $<$ mean. 
3.5.2. Independent Variables. Sociodemographic and economic variables such as maternal age, education level, marital status, age of the infant, and nature of work, other work-related factors that include lack of on-site child care, temporary separation of baby, and time of work, and other factors such as counseling about breastfeeding and deliver place of mothers were considered as independent variables under study.

3.6. Sample Size Determination. The required sample size of the study participants were determined by using a single population proportion formula.

$$
n=\frac{(Z \alpha / 2)^{2} P(1-P)}{d^{2}},
$$

where $n=$ is the minimum sample size required, $Z=$ critical value at $95 \%$ confidence interval (1.96), $P=$ reported prevalence which is $34.95 \%$ [15], and $d=$ margin of error between sample statistics and the population parameter (5\%).

$$
n=\frac{(Z \alpha / 2)^{2} P(1-P)}{d^{2}}=\frac{(1.96)^{2} * 0.3495(1-0.3495)}{(0.05)^{2}}=349 \text {. }
$$

Adding 10\% nonresponse rate, the sample size was 401 .

To determine sufficient sample size for representativeness of the study population, we used Epi Info software in sample size calculation of statistically significant factors of employed mother's exclusive breastfeeding practice from previous studies conducted in Ethiopia. The largest sample size was found from jobs offering leave with prevalence of 49.5 , an odds ratio of $1.86,80 \%$ of power, and in $95 \%$ CI with sample size of 409 . The final sample size, taking $10 \%$ none response rate, was 449 .

3.7. Sampling Technique. The study participants were selected through a stratified sampling technique. Government and private employees were considered as strata. Sampling frame/lists of all government- and private-employed mothers having children aged 6-23 months were obtained from district salary payrolls. According to Mecha district 2019 salary payroll and other enterprises, 1497 employees had children in the age of 6-23 months (960 government and 537 private employees). Sampling distribution with population proportion was performed in each stratum, and a simple random sampling technique was employed to get the required sample. The required study subjects in each stratum were identified using computer random number generator software from three-digit-number-coded sampling frames to get the required sample (449 women, 288 from the government, and 161 private sectors proportionally with respect to strata population) and sorted by the ascending order of numbers.

3.8. Data Collection and Procedures. A self-administered structured questionnaire adapted from different literatures $[1,12,14-20]$ and modified according to the local context by the investigators was used to collect data concerning different independent variables. Five nurse data collectors and 2 senior health officer supervisors were recruited, and they took one-day training about the variables and were assigned in different health institutions. The questionnaire was delivered by hand to the respondents at their duty stations during working hours through data collectors. It was issued and collected after a week to give respondents enough time to answer the questions.

3.9. Data Quality Assurance. To ensure the data quality, questionnaires were collected by data collectors who can speak the local language, and training was given to them. The data collection tools were pretested on 45 random samples for consistency of understanding, review of tools, and completeness of data items. Based on the pilot data result, the necessary amendments were made on the final questionnaire. The quality of data was controlled by supervisors and investigators. Any problem traced was immediately communicated to data collectors for giving corrections. All daily collected data were checked by the supervisor for completeness and consistency. Finally, the investigators monitored the overall quality of data collected.

3.10. Data Management and Analysis. After checking completeness, the data were entered into Epi Info (version 7.2.2.6) and exported to Statistical Package for Social Sciences (SPSS) version 23 for analysis. Data were edited, coded, summarized, and analyzed using descriptive and binary logistic regression methods which illustrated the diverse findings of the study. First, all factors were analyzed using bivariate analysis; of them, those predictors whose $p$ value $\leq 0.2$ had been selected for multivariate analysis. In multivariable logistic regression, variables that had $p$ value $\leq 0.05$ were statistical significant. A result of the study was presented in frequency tables and texts with clear labeling.

3.11. Ethical Considerations. Ethical approval was taken from the Bahirdar University ethical review committee. Mecha district health and administrative office approval was also obtained. Letters of cooperation from kebeles administrators were secured before data collection. The study neither involved any experiment on human subjects nor conducted without the consent of the study participants. Above all, the researcher did not ask the study participants to engage into risks as a result of participating in this study. Besides, informed verbal consent was obtained from the key respondents during data collection. The respondents were given the right to refuse or take part in the study. The primary data collection in the organization was conducted under the permission of the concerned bodies and without any offence in participants' interest. Privacy and confidentiality of information given by each respondent was kept properly through secured the gathered data from anyone. 


\section{Results}

4.1. Sociodemographic Characteristics. A total of 429 employed mothers participated in the study which makes the response rate of $96 \%$. The average age of the mother was 29 years with a standard deviation of \pm 5.8 . About $64.6 \%$ of respondents were of the age between 25-35 years. Among the respondents, $62 \%$ of them came back to their work after leave and $72 \%$ of employed mothers had maternity leave of more than 4 months. Among employed mothers, 64.1\% were government employed and the rest were private organization employed. About $54.8 \%$ of respondents had an education level of certificate and below. The majority of respondents $(71.1 \%)$ were urban citizens, and $92.8 \%$ of respondents were orthodox religion followers. Of the respondents, $66.7 \%$ got support from their husbands to breastfeed their baby (Table 1).

4.2. Child Characteristics. The study revealed that majority (83.2\%) of respondents' gestational ages at birth were 37-42 weeks, and $91.4 \%$ of respondents gave the current birth at the health facilities. About $47.1 \%$ of participants had another experience of delivery. Most of $(88.8 \%)$ the participants fed colostrum soon after birth. Only $10.5 \%$ of responds had a private place to express breast milk and breast feed in their workplace (Table 2).

4.3. Knowledge of Respondents towards Breast Feeding. Generally, $92.1 \%$ of respondents had good knowledge about exclusive breastfeeding. A majority (93.5\%) of mothers had knowledge on the essentiality of breast milk for a newly born baby. Many respondents in the current investigation $(90.9 \%)$ assured that breastfeeding increases the attachment of their baby with them. On the other hand, the majority of respondents $(83.9 \%)$ had knowledge about the immune system of breastfeeding for infants, and $78.6 \%$ of the respondents in the current study had knowledge that their babies should suck breast milk before a minimum of one day after birth (Table 3).

4.4. Mothers' Appropriate Practice towards Exclusive Breastfeeding. Only $38.5 \%$ of respondents had practiced appropriate exclusive breastfeeding. Majority of respondents $(88.8 \%)$ fed colostrum soon after giving birth to their babies. About $85.1 \%$ of respondents started initiating breastfeeding with 0-6 hours of birth (see Table 4).

4.5. Univariate and Multivariable Logistic Regression for Good Knowledge. First delivery for the participant, age of the mother, education level, maternity leave, actual time to return back to work, private place for breastfeeding in the institution, occupation, birth at health facilities, support of husband for breastfeeding, residence, and marital status were the significant explanatory variables in univariate analysis of knowledge (Table 5). Actual time to return back to work, residence, and marital status were statistical significant for multivariable logistic regression of knowledge.
TABLE 1: Sociodemographic characteristics and related information of respondents in Mecha district, Northwest Ethiopia, 2019 $(n=429)$.

\begin{tabular}{|c|c|c|c|}
\hline Variables & Category & Frequency & Percentage \\
\hline \multirow{2}{*}{$\begin{array}{l}\text { Actual time back to } \\
\text { work }\end{array}$} & $\begin{array}{c}\text { Less than } 4 \\
\text { months }\end{array}$ & 163 & 38.0 \\
\hline & $\begin{array}{l}4 \text { months and } \\
\text { above }\end{array}$ & 266 & 62.0 \\
\hline \multirow[t]{2}{*}{ Educational status } & $\begin{array}{c}\text { Certificate and } \\
\text { below }\end{array}$ & 235 & 54.8 \\
\hline & Above certificate & 194 & 45.2 \\
\hline \multirow{2}{*}{$\begin{array}{l}\text { Maternity leave } \\
\text { taken }\end{array}$} & $\begin{array}{l}\text { Less than } 4 \\
\text { months }\end{array}$ & 120 & 28.0 \\
\hline & $\begin{array}{l}4 \text { months and } \\
\text { above }\end{array}$ & 309 & 72.0 \\
\hline \multirow{2}{*}{ Occupation } & Government & 275 & 64.1 \\
\hline & Private & 154 & 35.9 \\
\hline \multirow{3}{*}{$\begin{array}{l}\text { Support from the } \\
\text { husband }\end{array}$} & No & 143 & 33.3 \\
\hline & Yes & 286 & 66.7 \\
\hline & Married & 403 & 93.9 \\
\hline \multirow[t]{3}{*}{ Marital status } & Divorced & 24 & 5.6 \\
\hline & Widowed & 2 & 0.5 \\
\hline & $<25$ & 69 & 16.1 \\
\hline \multirow[t]{2}{*}{ Age of the mother } & $25-35$ & 277 & 64.6 \\
\hline & $>35$ & 83 & 19.3 \\
\hline \multirow{2}{*}{ Residence } & Urban & 305 & 71.1 \\
\hline & Rural & 124 & 28.9 \\
\hline \multirow{3}{*}{ Religion } & Orthodox & 398 & 92.8 \\
\hline & Muslim & 24 & 5.6 \\
\hline & Others & 7 & 1.6 \\
\hline
\end{tabular}

The employed mothers whose actual time to return back to their work is less than four months were less likely to have good knowledge as compared to those employed mothers whose actual time to come back to their work place is more than four months $(\mathrm{AOR}=0.15 ; 95 \% \mathrm{CI}:(0.04-0.67), p$ value $=0.01)$. On the other hand, the employed mothers who lived in an urban area were 3.09 times more likely to have good knowledge as compared to employed mothers who lived in a rural area $(\mathrm{AOR}=3.09,95 \% \mathrm{CI}$; $(1.12-8.50), p$ value $=0.03$ ). Employed mothers who were married were 5.6 times more likely to have good knowledge as compared to widowed employed mothers $(\mathrm{AOR}=5.6,95 \% \mathrm{CI}$ : $(1.21-9.62), p$ value $=0.04)($ Table 5$)$.

4.6. Univariate and Multivariable Logistic Regression for Appropriate Exclusive Breast Feeding Practice. Similarly variables that stated significant explanatory variables under univariates analysis of knowledge were also significant explanatory variables in univariate analysis of practice (Table 6). From these, educational level, maternity leave, actual time to return back to work, and support of the husband for breastfeeding were statistical significant for multivariable logistic regression of practice. Employed mothers whose actual time to return back their work is less than four months were less likely to have good practice compared with employed mothers whose actual time to return back to their work place is more than four months $(\mathrm{AOR}=0.21 ; 95 \% \mathrm{CI}$ : $(0.08-0.51), p$ value $=0.01)$. Participants whose educational 
TABLe 2: Respondents' child characteristics and related information in Mecha district, Northwest Ethiopia, 2019 ( $n=429$ ).

\begin{tabular}{|c|c|c|c|}
\hline Variables & Category & Frequency & Percentage \\
\hline \multirow{2}{*}{ Feed the colostrum soon after birth } & No & 48 & 11.2 \\
\hline & Yes & 381 & 88.8 \\
\hline \multirow{2}{*}{ Is this your first child? } & No & 202 & 47.1 \\
\hline & Yes & 227 & 52.9 \\
\hline \multirow{2}{*}{ Have a private place to express breast milk } & No & 384 & 89.5 \\
\hline & Yes & 45 & 10.5 \\
\hline \multirow{3}{*}{ Gestational age (at birth) } & $37-42$ weeks & 357 & 83.2 \\
\hline & $<37$ weeks & 29 & 6.8 \\
\hline & $>42$ weeks & 43 & 10 \\
\hline \multirow{2}{*}{ Current child birth at health facilities } & No & 37 & 8.6 \\
\hline & Yes & 392 & 91.4 \\
\hline
\end{tabular}

TABle 3: Respondents' knowledge towards breastfeeding in Mecha district, Northwest Ethiopia, $2019(n=429)$.

\begin{tabular}{|c|c|c|c|}
\hline Variables & Category & Frequency & Percentage \\
\hline \multirow{2}{*}{ Had good knowledge (say yes $\geq$ mean of the following ten questions) } & No & 34 & 7.9 \\
\hline & Yes & 395 & 92.1 \\
\hline \multirow{2}{*}{ Breastfed children are more benefitted than formula milk-fed children. } & No & 96 & 22.4 \\
\hline & Yes & 333 & 77.6 \\
\hline \multirow{2}{*}{ Breast milk contains all the essential nutrients for a newborn child } & No & 28 & 6.5 \\
\hline & Yes & 401 & 93.5 \\
\hline \multirow{2}{*}{ Breastfeeding is a good contraceptive method } & No & 116 & 27 \\
\hline & Yes & 313 & 73 \\
\hline \multirow{2}{*}{ Semisolid/solid foods should be introduced to the baby at six months of age } & No & 47 & 11 \\
\hline & Yes & 382 & 89 \\
\hline \multirow{2}{*}{ Exclusive breastfeeding does not prohibit giving water to the infant } & No & 215 & 50.1 \\
\hline & Yes & 214 & 49.9 \\
\hline \multirow{2}{*}{ Breastfeeding promotes mother-baby attachment } & No & 39 & 9.1 \\
\hline & Yes & 390 & 90.9 \\
\hline \multirow{2}{*}{ Immune systems of breastfed infants are more developed than those of formula-fed infants } & No & 360 & 83.9 \\
\hline & Yes & 69 & 16.1 \\
\hline \multirow{2}{*}{ Feed initial yellow breast milk (colostrum) soon after birth to your new baby } & No & 48 & 11.2 \\
\hline & Yes & 381 & 88.8 \\
\hline \multirow{2}{*}{ Colostrum is nutritionally useless for the baby and should be discarded } & No & 350 & 81.6 \\
\hline & Yes & 79 & 18.4 \\
\hline \multirow{2}{*}{ A new-born baby should suck breast milk before a minimum of one day following delivery } & No & 92 & 21.4 \\
\hline & Yes & 337 & 78.6 \\
\hline
\end{tabular}

TABle 4: Practice of employed mothers towards exclusive breastfeeding in Mecha district, Northwest Ethiopia, 2019 ( $n=429$ ).

\begin{tabular}{|c|c|c|c|}
\hline Characteristics & Category & Frequency & Percentage \\
\hline \multirow{2}{*}{ Did you provide any additional food for your current child within the first six months? } & No & 173 & 40.3 \\
\hline & Yes & 256 & 59.7 \\
\hline \multirow{2}{*}{ Did you give water for your current child during the first six months? } & No & 165 & 61.5 \\
\hline & Yes & 264 & 38.5 \\
\hline \multirow{4}{*}{ When did you start first breastfeeding? } & $0-6$ hours & 365 & 85.1 \\
\hline & $7-12$ hours & 39 & 9.0 \\
\hline & 13-24 hours & 11 & 2.6 \\
\hline & $\begin{array}{l}\text { After the first } \\
\text { day }\end{array}$ & 14 & 3.3 \\
\hline \multirow{2}{*}{ Did you feed the colostrum soon after birth to your new baby? } & No & 48 & 11.2 \\
\hline & Yes & 381 & 88.8 \\
\hline \multirow{2}{*}{$\begin{array}{l}\text { Appropriate exclusive breastfeeding practice (feeding of child only breast milk for the first six } \\
\text { months except prescribed medications) }\end{array}$} & No & 264 & 61.5 \\
\hline & Yes & 165 & 38.5 \\
\hline
\end{tabular}

level is greater than certificate were 2.97 times more likely to have good practice in exclusive breastfeeding as compared to those employed mothers whose education level is less or equal to certificate $(\mathrm{AOR}=2.97,95 \% \mathrm{CI}$ : $(1.66-5.34), p$ value $<0.001)$. Employed mothers who got maternity leave less than four months were less likely to have good practice as 
TABle 5: The univariate and multivariate logistic regression analysis for knowledge of employed mothers in Mecha district, Northwest Ethiopia, $2019(n=429)$.

\begin{tabular}{|c|c|c|c|c|c|c|}
\hline Variables & Category & $\begin{array}{l}\text { Poor knowledge } \\
\quad(n=37)\end{array}$ & $\begin{array}{c}\text { Good knowledge } \\
(n=392)\end{array}$ & COR $(95 \%$ CI $)$ & $\operatorname{AOR}(95 \% \mathrm{CI})$ & $\begin{array}{c}p \text { value for COR/ } \\
\text { AOR }\end{array}$ \\
\hline \multirow{2}{*}{ First baby } & No & 19 & 183 & $0.83(0.42,1.63)$ & $0.87(0.21,3.62)$ & $0.07 / 0.61$ \\
\hline & Yes & 18 & 209 & 1 & 1 & \\
\hline \multirow{3}{*}{ Age of the mother } & $<25$ & 12 & 57 & $0.50(0.19,1.32)$ & $\begin{array}{l}0.94(0.22 \\
\quad 4.04)\end{array}$ & $0.16 / 0.93$ \\
\hline & $25-35$ & 17 & 260 & $1.63(0.68,3.92)$ & $\begin{array}{l}1.85(0.52 \\
6.57)\end{array}$ & $0.27 / 0.34$ \\
\hline & $>35$ & 8 & 75 & 1 & 1 & \\
\hline \multirow{2}{*}{ Educational level } & $<$ certificate & 25 & 210 & $0.55(0.27,1.13)$ & $1.05(0.36,3.10)$ & $0.10 / 0.93$ \\
\hline & Certificate and above & 12 & 182 & 1 & 1 & \\
\hline \multirow{2}{*}{ Maternity leave } & $<4$ months & 22 & 98 & $0.23(0.11,0.46)$ & $0.75(0.18,3.18)$ & $0.00 / 0.70$ \\
\hline & $\geq 4$ months & 15 & 294 & 1 & 1 & \\
\hline \multirow{2}{*}{ Actual time to return back to work } & $<4$ months & 28 & 135 & $0.17(0.08,0.37)$ & $0.15(0.04,0.67)$ & $0.00 / 0.01^{* *}$ \\
\hline & $\geq 4$ months & 9 & 257 & 1 & 1 & \\
\hline \multirow{2}{*}{$\begin{array}{l}\text { Have a private place for } \\
\text { breastfeeding }\end{array}$} & No & 35 & 349 & $0.46(0.11,2.06)$ & $0.41(0.06,2.72)$ & $0.18 / 0.36$ \\
\hline & Yes & 2 & 43 & 1 & 1 & \\
\hline \multirow[t]{2}{*}{ Occupation } & $\begin{array}{l}\text { Government } \\
\text { employee }\end{array}$ & 14 & 261 & $3.1(1.55,6.55)$ & $\begin{array}{l}1.79(0.48 \\
6.70)\end{array}$ & $0.002 / 0.39$ \\
\hline & Private employee & 22 & 132 & 1 & 1 & \\
\hline \multirow{2}{*}{ Birth at health facilities } & No & 8 & 34 & $0.34(0.14,0.81)$ & $1.65(0.41,6.67)$ & $0.01 / 0.39$ \\
\hline & Yes & 29 & 358 & 1 & 1 & \\
\hline \multirow{2}{*}{ Support of the husband } & No & 17 & 126 & $0.56(0.26,1.08)$ & $0.66(0.21,2.06)$ & $0.09 / 0.47$ \\
\hline & Yes & 20 & 266 & 1 & 1 & \\
\hline \multirow[b]{2}{*}{ Residence } & Urban & 19 & 286 & $2.56(1.3,5.06)$ & $3.1(1.12,8.57)$ & $0.007 / 0.03^{* *}$ \\
\hline & Rural & 18 & 106 & 1 & 1 & \\
\hline \multirow{3}{*}{ Marital status } & Married & 27 & 376 & $\begin{array}{c}13.9(0.85 \\
228.8)\end{array}$ & $5.6(1.21,9.62)$ & $0.06 / 0.04^{* *}$ \\
\hline & Divorced & 9 & 15 & $\begin{array}{c}1.67(0.90 \\
30.06)\end{array}$ & $\begin{array}{c}2.77(0.9 \\
12.98)\end{array}$ & $0.73 / 0.13$ \\
\hline & Widowed & 1 & 1 & 1 & 1 & \\
\hline
\end{tabular}

compared to those employed mothers who got maternity leave greater or equal to four months $(\mathrm{AOR}=0.31,95 \% \mathrm{CI}$ : $(0.10-0.91), p$ value $=0.03)$. Women who did not get support from their husbands to use exclusive breast milk were less likely to have good practice in exclusive breastfeeding as compared to those employed mothers who got support from their husbands $(\mathrm{AOR}=0.26,95 \%$ CI $(0.14-0.47), p$ value $<0.001$ ) (Table 6).

\section{Discussion}

In this study, among employed mothers, $92.1 \%$ of them had good knowledge towards exclusive breastfeeding, and this finding was consistent with a study conducted in Ambo (90.8\%) [17] and was greater than a study conducted in Kigali (74.4\%), Axum town, and Gondar town $(70 \%)[15,18,19]$, respectively. But, it is less than the study conducted in Injibara (96.3\%) [21]. The possible reason might be the time of study.

Consistent with [22], the current study indicates that exclusive breastfeeding practice was $38.5 \%$, but this is much lower than the WHO recommendation on exclusive breastfeeding, 90\%. The possible reason might be lower breastfeeding centers at the working place and no enough time for maternity leave. This finding is also in line with the findings of a study conducted in Ruanda Kigali (34.4\%) and Debre Markos (34.5\%) $[15,18]$, respectively. The finding of this study is greater than the study conducted in Jordan (20.9\%), USA (22\%), Bangladesh Ad-Din Hospital (21\%), and Gondar (20.9\%) [23-26], respectively.

Employed mothers who had maternity leave greater than four months had appropriate practice in exclusive breastfeeding as compared to those employed mothers who had maternity leave less than four months. This finding is supported by one of the previous research [15]. The association between exclusive breastfeeding practice and the duration of materiality leave is also in line with the findings of the study conducted in Australia [27]. The potential reason for this might be that mothers who got extended maternity leave might be free from their normal work load in their work place to give attention for their child and the maternity leave period less than four months might be too short considering that the recommended period of exclusive breastfeeding was 6 months.

The level of education plays a significant role for the practice of exclusive breastfeeding, and the result related to this finding is supported by the previous investigation [20]. Employed mothers who have high level of education acquired better information and practice of exclusive breastfeeding. Hence, employed mothers with low level of education had inadequate information about exclusive breastfeeding. Mothers educated higher than certificate may be more exposed to the media and have better understanding on nutrition and health of their infant. They may also have greater authority to improve their family and childhood survival strategies, such as appropriate exclusive breastfeeding.

In the current study, it is declared that those employed mothers who got support from their husbands for breastfeeding had better practice in exclusive breastfeeding. Employed mothers who were not supported by their husbands less likely practiced exclusive breastfeeding as compared to employed mothers who were supported by their husbands which in line with previous research which was conducted in Goba district, Southeast 
TABLE 6: The univariate and multivariate logistic regression analysis for practice of employed mothers in Mecha district, Northwest Ethiopia, $2019(n=429)$.

\begin{tabular}{|c|c|c|c|c|c|c|}
\hline Variables & Category & $\begin{array}{l}\text { Poor practice } \\
\quad(n=264)\end{array}$ & $\begin{array}{l}\text { Good practice } \\
\quad(n=165)\end{array}$ & COR $(95 \% \mathrm{CI})$ & AOR $(95 \% \mathrm{CI})$ & $\begin{array}{c}p \text { value for COR/ } \\
\text { AOR }\end{array}$ \\
\hline \multirow{3}{*}{ First baby } & No & 122 & 80 & $1.1(1.23,13.87)$ & $1.06(0.44,2.59)$ & $0.05 / 0.89$ \\
\hline & Yes & 142 & 85 & 1 & & \\
\hline & $<25$ & 46 & 23 & $0.8(0.30,0.83)$ & $1.10(0.42,2.92)$ & $0.03 / 0.81$ \\
\hline \multirow[t]{2}{*}{ Age of the mother } & $25-35$ & 167 & 110 & $1.05(1.52,2.84)$ & $\begin{array}{c}0.871 \\
(0.44,1.72)\end{array}$ & $0.04 / 0.84$ \\
\hline & $>35$ & 51 & 32 & 1 & 1 & \\
\hline \multirow{2}{*}{ Educational level } & $\leq$ certificate & 129 & 106 & $1.9(1.26,2.8)$ & $2.97(1.66,5.3)$ & $0.002 / 0.00^{* *}$ \\
\hline & $>$ certificate & 135 & 59 & 1 & 1 & \\
\hline \multirow{2}{*}{ Maternity leave } & $<$ four months & 96 & 24 & $0.29(0.18,0.49)$ & $0.31(0.10,0.91)$ & $0.00 / 0.03^{* *}$ \\
\hline & $\geq$ four months & 168 & 141 & 1 & 1 & \\
\hline \multirow{2}{*}{ Actual time to return back to work } & $<$ four months & 131 & 32 & $0.24(0.16,0.39)$ & $0.21(0.08,0.51)$ & $0.00 / 0.01^{* *}$ \\
\hline & $\geq$ four months & 133 & 133 & 1 & 1 & \\
\hline \multirow{3}{*}{ Private place for breastfeeding } & No & 243 & 141 & $0.50(0.27,0.94)$ & $0.92(0.40,2.13)$ & $0.03 / 0.84$ \\
\hline & Yes & 21 & 24 & 1 & 1 & \\
\hline & Gov. employee & 169 & 106 & $1.01(0.67,1.52)$ & $0.98(0.49,1.96)$ & $0.18 / 0.96$ \\
\hline Occupation & $\begin{array}{l}\text { Private } \\
\text { employee }\end{array}$ & 95 & 59 & 1 & 1 & \\
\hline \multirow{2}{*}{ Birth at health facilities } & No & 28 & 14 & $0.78(0.39,1.53)$ & $0.85(0.32,2.26)$ & $0.07 / 0.75$ \\
\hline & Yes & 236 & 151 & 1 & 1 & \\
\hline \multirow{2}{*}{$\begin{array}{l}\text { Support of the husband for } \\
\text { breastfeeding }\end{array}$} & No & 103 & 40 & $0.5(0.32,0.77)$ & $0.26(0.14,0.47)$ & $0.002 / 0.00^{* *}$ \\
\hline & Yes & 161 & 125 & 1 & 1 & \\
\hline \multirow{2}{*}{ Residence } & Urban & 184 & 121 & $1.19(0.77,1.85)$ & $1.42(0.74,2.74)$ & $0.06 / 0.29$ \\
\hline & Rural & 80 & 44 & 1 & 1 & \\
\hline \multirow{3}{*}{ Marital status } & Married & 247 & 156 & $\begin{array}{l}0.63(0.04 \\
10.17)\end{array}$ & $0.59(0.04,8.59)$ & $0.13 / 0.70$ \\
\hline & Divorced & 16 & 8 & $0.50(0.03,9.07)$ & $\begin{array}{c}3.00 \\
(0.16,57.26)\end{array}$ & $0.41 / 0.47$ \\
\hline & Widowed & 1 & 1 & 1 & 1 & \\
\hline
\end{tabular}

Note: ${ }^{* *}=$ variables which are significantly associated in multivariable analysis. $p$ value for COR/AOR $=0.00 / 0.03$ means $p$ value for COR $=0.00$ and $p$ value for $\mathrm{AOR}=0.03$

Ethiopia [16]. The possible reason might be that when partners involved, the mothers will have enough time and also become economically stable. Mothers might be in pain after the delivery of their baby, have problem with holding and positioning the baby, and need extra help for breastfeeding. Consequently, husbands' support might be very important at this stage, and the support can significantly encourage mothers to advance breastfeeding performances, to overcome breastfeeding challenges and to build up their confidence level.

Similar with findings of the study in [28-30], this study revealed that those employed mothers who came back to their work after four months of delivery had better EBF practice than those who came back before four months. Hence, even though employed mothers who come back to work before four months have good knowledge about the use of exclusive breastfeeding, they cannot practice it practically because such mothers may be forced to detach from their babies at working hours and introduce formula milk for their infants earlier as compared to employed women who return to work greater than 4 months.

\section{Limitations of the Study}

Since the data were collected at the work place of employed mothers, they need to give attention for their work rather than the questionnaires. Infants exclusive breastfeeding practices were determined on maternal selfreport, and recall biases, especially for those who had older children, might occur. Since the study was cross sectional, it shows only the temporal relationship between variables.

\section{Conclusions and Recommendation}

Marital status, residence, and actual times of mothers to return back to work were statically significant for mothers' good knowledge towards EBF. Mothers' level of education, support from husbands, maternity leave, and actual time of mothers to return back to their work place were statistically significant for appropriate practice of exclusive breastfeeding. Generally, the level of exclusive breastfeeding practice among employed mothers in the study area was low as compared with the World Health Organization (WHO) recommendation. Actual time to return to work from leave was statistically associated for both knowledge and practice of exclusive breastfeeding. For employed mothers, it is advisable to use their annual leave after the end of the maternity leave. Husbands should actively support their wives in the practice of exclusive breastfeeding. For the policy makers, it is advisable to revise the existing maternity leave to extend for some additional months. Government should work on mothers' education to increase the exclusive breastfeeding practice. 


\section{Abbreviations}

CHIS: Community health information system

CSA: Central Statistics Agency

EBF: $\quad$ Exclusive breastfeeding

EDHS: Ethiopia demographic health survey

OBF: $\quad$ Optimum breastfeeding

SPSS: $\quad$ Statistical Package for Social Science

UNICEF: United Nations International Children Fund

WHO: World Health Organization.

\section{Data Availability}

The datasets analyzed during the current study are available with the corresponding author on reasonable request.

\section{Conflicts of Interest}

The authors declare that there are no conflicts of interest regarding the publication of this paper.

\section{Authors' Contributions}

Amare Lisanu Mazengia wrote the proposal, participated in data collection, analyzed the data, wrote the result, revised subsequent drafts of the paper, and drafted the manuscript. Hibru Demissie wrote the proposal, participated in data collection, analyzed the data, wrote the result, revised subsequent drafts of the paper, and drafted the manuscript. Both authors contributed equally.

\section{Acknowledgments}

First, the authors would like to acknowledge Bahir Dar University for helping in order to get continuous correction comments and research presentations in the institutional repository link of https://ir.bdu.edu.et/bitstream/handle/ 123456789/10191/Hibru_Demisie_June_2019_Final_Thesis. pdf? sequence $=1$ \&isAllowed $=y$. Next, the authors would like to acknowledge Mecha District Office for their support in giving them the necessary data. The authors would also like to express their deepest gratitude to the participants, supervisors, and data collectors for the fulfillment of the research.

\section{References}

[1] WHO, Exclusive Breast Feeding and its Impact in Infants of under Six Months, WHO, Geneva, Switzerland, 2006.

[2] S. Inch, S. Law, and L. Wallace, "Hands off! the breast feeding best start project," The Practicing Midwife, vol. 6, no. 10, pp. 17-19, 2003.

[3] U. D. Parashar, E. G. Hummelman, J. S. Bresee, M. A. Miller, and R. I. Glass, "Global illness and deaths caused by rotavirus disease in children," Emerging Infectious Diseases, vol. 9, no. 5, p. 565, 2003.

[4] D. James and R. Lessen, "Position of the American Dietetic Association: promoting and supporting breastfeeding," Journal of the American Dietetic Association, vol. 109, no. 11, pp. 1926-1942, 2009.
[5] S. J. Klees and O. Qargha, "Equity in education: the case of UNICEF and the need for participative debate," Prospects, vol. 44, no. 3, pp. 321-333, 2014.

[6] UNICEF, The State of the World's Children 2011: AdolescenceAn Age of Opportunity, Unicef, New York, NY, USA, 2011.

[7] WHO and UNICEF, Pregnancy, Childbirth, Postpartum, and Newborn Care: A Guide for Essential Practice, WHO, Geneva, Switzerland, 2003b.

[8] WHO and UNICEF, Global Strategy for Infant and Young Child Feeding, World Health Organization, 20 Avenue Appia, 1211 Geneva 27, Switzerland, 2003.

[9] G. Jones, R. W. Steketee, R. E. Black, Z. A. Bhutta, S. S. Morris, and B. C. S. S. Group, "How many child deaths can we prevent this year?" Lancet, vol. 362, no. 9377, pp. 65-71, 2003.

[10] HIV/AIDS, JUNPo, and UNICEF, Children and AIDS: Fifth Stocktaking Report, 2010, UNICEF, New York, NY, USA, 2010.

[11] UNICEF, Progress for Children: Achieving the MDGs with Equity, Unicef, New York, NY, USA, 2010.

[12] E. CSA, Ethiopian Demographic and Health Survey Addis Ababa, Ethiopia, Ministery of Health, Rockville, ML, USA, 2016.

[13] F. Tadesse, S. Shine, H. Asresahegn, Y. Alemayehu, and T. Tadesse, "Exclusive breastfeeding and maternal employment among mothers of infants from three to five months old in the Fafan zone, Somali regional state of Ethiopia: a comparative cross-sectional study," BMC Public Health, vol. 19, no. 1, p. 1015, 2019.

[14] T. G. Woldie, A. W. Kassa, and M. Edris, "Assesment of exclusive breast feeding practice for the first six months and associated factors among mothers having children in the age of 6-12 months," Science Journal of Public Health, vol. 2, no. 4, pp. 330-336, 2014.

[15] M. Alemayehu, K. Abreha, H. Yebyo, K. Zemichael, and H. Gebremichael, "Factors associated with timely initiation and exclusive breast feeding among mothers of Axum town, northern Ethiopia," Science Journal of Public Health, vol. 2, no. 5, pp. 394-401, 2014.

[16] T. Alemayehu, J. Haidar, and D. Habte, "Determinants of exclusive breastfeeding practices in Ethiopia," Ethiopian Journal of Health Development, vol. 23, no. 1, 2009.

[17] Z. B. Bayissa, B. K. Gelaw, A. Geletaw et al., "Knowledge and practice of mothers towards exclusive breastfeeding and its associated factors in Ambo Woreda West Shoa Zone Oromia region, Ethiopia," Epidemiology: Open Access, vol. 5, no. 1, 2015.

[18] B. Jino, P. Munyanshongore, and B. Mwuayuma, Knowledge, Attitudes and Practice of Exclusive Breast-Feeding of Infants Aged 0-6months by Urban Refugee Women in Kigali, National University of Rwanda, Rwanda, 2011.

[19] Y. T. Nigatu and N. Worku, "Optimal breastfeeding practice and associated factors amongst working mothers in northern Ethiopia," East African Journal of Public Health, vol. 11, no. 1, 2014.

[20] T. Setegn, T. Belachew, M. Gerbaba, K. Deribe, A. Deribew, and S. Biadgilign, "Factors associated with exclusive breastfeeding practices among mothers in Goba district, south east Ethiopia: a cross-sectional study," International Breastfeeding Journal, vol. 7, no. 1, p. 17, 2012.

[21] Y. T. Dile and R. Srinivasan, "Evaluation of CFSR climate data for hydrologic prediction in data-scarce watersheds: an application in the Blue Nile river basin," Journal of the American Water Resources Association, vol. 50, no. 5, pp. 1226-1241, 2014. 
[22] L. Victora, J. Sandra, and G.-S. Laurence, "Maternal obesity and breast-feeding practices," The American Journal of Clinical Nutrition, vol. 77, no. 4, pp. 931-936, 2003.

[23] M. Alemayehu, Determinants of Customer Based Brand Equity Among Pharmaceutical Prescribers in the Case of Addis Ababa Health Bureau Hospitals, St. Mary's University, Addis Abeba, Ethiopia, 2017.

[24] L. F. C. Bullock, M. K. Libbus, S. Lewis, and D. Gayer, "Continuing education: improving perceived competence in school nurses," The Journal of School Nursing, vol. 18, no. 6, pp. 360-363, 2002.

[25] F. M. Kibengo, E. Ruzagira, D. Katende et al., "Safety, adherence and acceptability of intermittent tenofovir/emtricitabine as HIV pre-exposure prophylaxis (PrEP) among HIVuninfected Ugandan volunteers living in HIV-serodiscordant relationships: a randomized, clinical trial," PLoS One, vol. 8, no. 9, p. e74314, 2013.

[26] M. Ng, T. Fleming, M. Robinson et al., "Global, regional, and national prevalence of overweight and obesity in children and adults during 1980-2013: a systematic analysis for the global burden of disease study 2013," The Lancet, vol. 384, no. 9945, pp. 766-781, 2014.

[27] J. P. Smith, S. Javanparast, E. McIntyre, L. Craig, K. Mortensen, and C. Koh, "Discrimination against breastfeeding mothers in childcare," Australian Journal of Labour Economics, vol. 16, no. 1, p. 65, 2013.

[28] J. D. Allan, P. B. McIntyre, S. D. P. Smith et al., "Joint analysis of stressors and ecosystem services to enhance restoration effectiveness," Proceedings of the National Academy of Sciences, vol. 110, no. 1, pp. 372-377, 2013.

[29] N. C. Rollins, N. Bhandari, N. Hajeebhoy et al., "Why invest, and what it will take to improve breastfeeding practices?" The Lancet, vol. 387, no. 10017, pp. 491-504, 2016.

[30] J. P. Smith, E. McIntyre, L. Craig, S. Javanparast, L. Strazdins, and K. Mortensen, "Workplace support, breastfeeding and health," Family Matters, no. 93, p. 58, 2013. 